\title{
Charge characteristics in relation to free iron and organic matter of soils from Bambouto Mountains, Western Cameroon
}

\begin{abstract}
We have examined the charge characteristics, with special emphasis on the role of free $\mathrm{Fe}$ and organic matter, of humid tropical soils from Bambouto Mountains, Western Cameroon. The soils, which are formed from tuff, basalt and trachyte, are dominated by kaolinite and sesquioxides. The mounts of Fe oxides in them increase somewhat with depth. Open 2:1 phyllosilicates are present in trace amounts. The point of zero charge of the variable charge components, $\mathrm{pH}$, is around 4 in the topsoil $(0-20 \mathrm{~cm})$ and around 6 at 100-150 cm depth. In the subsoils, $\mathrm{pH} 0$ exceeds soil $\mathrm{pH}$ presumably because of large quantities of Fe oxides. Deferration increases both soil $\mathrm{pH}$ and $\mathrm{pH}$, but diminishes the anion exchange capacity. Oxides and oxyhydrates of Fe have positive surface charge, so their removal from the soils would result in overall loss of positive charge. Increases in soil $\mathrm{pH}$ would bring about an increase in the cation exchange capacity of the soils. Hence, management practices that reduce soil acidity should reduce loss of essential basic cations via leaching.
\end{abstract}

Keyword: Charge characteristics; Soils; Iron 